\title{
Conditions of soils dilution of dams under seismic impacts
}

\author{
Khayat Rasulov* \\ Tashkent Institute of architecture and Civil Engineering, Tashkent, Uzbekistan
}

\begin{abstract}
This report presents the results of the author's research on the dilution of water-saturated cohesive soils in the conditions of concussions. The nature of the weakening of the soil connectivity during vibration and the dynamic pressure that occurs in the thickness during the compaction of the disturbed soil structures, which contribute to the liquefaction and spreading of the soil from the body of the structure, is described. The criterion of the possibility of violation of the soil structure in the conditions of concussions is given. A theoretical method for determining this important indicator of the seismic strength of the soil is given.
\end{abstract}

\section{Introduction}

The development and improvement of methods of dynamic liquefaction of water-saturated sandy soils were carried out by Russian [1-4], Japanese [5-8], the USA [9-12], Uzbek [1520], etc. However, they did not consider the dynamic liquefaction of cohesive soils, which sharply differ in properties from sand, which was the object of research of the author and his students [17-20]. The report focuses on changes in the cohesion of the soil and the dynamic pressure that contributes to the duration of the soil.

\section{Methods}

At present, it is an indisputable fact that the degree of disturbance of the structure of watersaturated soils during shaking, and hence their dynamic mode, is determined by the impact of only a certain part of the dynamic (seismic) load applied to them.

This load is estimated by the value of the maximum seismic acceleration characteristic of the resulting oscillation $-\alpha_{s .}$.

Denoting the active part of the oscillation acceleration through the $\alpha_{c}$ you can write

$$
\alpha_{c}=\alpha_{s}-\alpha_{\text {lim }}
$$

Here $\alpha_{\text {lim }}$ is threshold acceleration, the acceleration limit, redeemable within soil thickness of the forces acting in these resistances, in the first place, the forces of adhesion

\footnotetext{
*Corresponding author: hayat1941@mail.ru
} 
$\left(c_{w}\right)$ and internal friction of soil $\left(\varphi_{w}\right)$.

Under this condition, the value of $\alpha_{\lim }$ is considered as a criterion expressed in acceleration, at which the oscillating soil retains its static structure, and liquefaction does not occur in it. To determine the $\alpha_{\text {lim }}$, the author proposed the formula [19]:

$$
a_{l i m}=\frac{2 \pi g\left(\sigma_{d} \operatorname{tg} \varphi_{w}+c_{w}\right)}{\gamma_{w} T_{o} v_{c} \sin 2 \pi_{\bar{\lambda}}^{z}}
$$

where: $\mathrm{g}$ is acceleration of gravity; $\sigma_{d}$ is dynamic tension of the weight of structures; $\gamma_{w}$ is density of the soil when moisture $\mathrm{w} ; T_{o}$ is period soil vibration; $v_{\mathrm{c}}$ are speed transverse seismic waves; $\mathrm{z}$ is the depth of the considered horizon; $\lambda$ is the wavelength of the seismic waves;

Obviously, the higher the value of the $\alpha_{\text {lim }}$, the smaller the acceleration of the $\alpha_{c}$, which determines the dynamic regime of the soil layer, is.

The relationship of the threshold acceleration of $\alpha_{\text {lim }}$ with the strength characteristics of the soil according to N. N. Maslov is expressed in the form:

$$
\alpha_{l i m}=\xi\left(p_{n} \operatorname{tg} \varphi_{w}+c_{w}\right),
$$

Following formula (3), change the value $\alpha_{\text {lim }}$ under seismic vibrations may occur due to the partial or complete reduction of the strength of the soil, such as normal tension $\left(p_{n}\right)$, friction angle $\left(\varphi_{w}\right)$ and cohesion $\left(c_{w}\right)$ that is associated with all other conditions with an increase in time the value of the calculated acceleration, contributing to the disruption of the structure and liquefaction of the soil, with all the ensuing consequences.

The disclosure of the nature of the violation of the stability of cohesive soils is reduced to identifying the parameters of the soil strength that change during shaking, which is described in detail in the physical theory "liquefaction of moist loess" [19]. At the same time, the decrease in the dynamic strength of the soil occurs due to the weakening of the cohesion forces $\left(c_{w}\right)$ in time, which determine the structural strength of the soil and the influence of the backpressure that occurs under these conditions due to the dynamic pressure $h_{z}$. As for the change in the angle of internal friction, it is a small amount.

The change in the strength of cohesive $\left(c_{w}\right)$ in the process of soil vibration occurs according to:

$$
\mathrm{c}_{\mathrm{w}}(t)=\mathrm{c}_{\mathrm{w}}(e)+\left[\mathrm{c}_{\mathrm{w}}(s)-\mathrm{c}_{\mathrm{w}}(e)\right] e^{-\mu \mathrm{t}}
$$

where: $\mathrm{c}_{\mathrm{w}}(s), \mathrm{c}_{\mathrm{w}}(e), \mathrm{c}_{\mathrm{w}}(t)$ are respectively, start, end, and the time values of the cohesive of the soil. $\mu$ is parameter that takes into account the possibility of the transition of soils to a liquefied state.

To determine the dynamic pressure of $h_{z}$ that occur in the soil column when the seal is broken, the cohesive of the particles of the formula [19]:

$$
h(z, t)=\frac{v_{0}}{2 k_{\phi}} H^{2}\left(e^{-\mu t}-e^{-\lambda t}\right)
$$

where $h(z, t)$ is quantity of the dynamic pressure at time $\mathrm{t}$ in the process of shaking; $k_{\phi}$ is filtration coefficient of the soil; $H$ is thickness of the oscillating layer; $\mu, \lambda$ are dynamic parameters experimentally determined; $v_{o}$ is the coefficient of dynamic consolidation, indicating the speed of compaction, calculated according to the formula: 


$$
v_{o}=\frac{d n}{d t}
$$

where: $n$ is the density (porosity) of the soil.

The next stage of the study included an experimental study to reveal the nature of the violation of soil cohesive $\left(c_{w, t}\right)$ and the conditions for the occurrence and further changes in the dynamic pressure $h_{z, t}$ during the shaking process.

\section{Results and Discussion}

The studies were carried out under laboratory conditions with loess on a directional vibration

unit. To obtain comparative indicators, the experiments were carried out at a constant value of the oscillation frequency by changing the amplitude or vice versa. The soil cohesive during the oscillation was measured using a special ball mounted on the soil surface. The dynamic pressure was measured using strain gauges at different points along the sample height. And the soil sediment was recorded using an indicator.

Analysis of the results of experiments conducted on loess soils moistened to varying degrees showed that the beginning of soil deformation during the shaking process corresponds to 15-20 seconds and more since the application of a dynamic load on the soil, which is a distinctive feature of cohesion soils from disconnected ones. The intensity of the concussion in these cases was measured in the range of $1200-1800 \mathrm{~mm} / \mathrm{s} 2$. At the same time, the pressure in the water begins to increase from some point after the application of a dynamic load on the soil, which indicates the onset of a violation of the soil structure under conditions $\alpha>a_{\text {lim. }}$.

Table 1 shows the results of one cycle of experiments conducted with loess soils.

Table 1. Changes in water pressure, ball deformation, and soil surface precipitation over time (Concussion intensity a $=1900 \mathrm{~mm} / \mathrm{s}^{2}$ )

\begin{tabular}{|c|c|c|c|c|c|c|c|c|c|}
\hline $\begin{array}{c}\text { Type of experimental } \\
\text { measurement }\end{array}$ & \multicolumn{10}{|c|}{ The duration of concussion, s } \\
\hline $\begin{array}{c}\text { The pressure in } \\
\text { water, mm }\end{array}$ & 8 & 12 & 15 & 20 & 30 & 45 & 50 & 60 & 90 \\
\hline Ball immersion, mm & 3 & 6 & 10 & 10 & 16 & 20 & 22 & 24 & 24 \\
\hline $\begin{array}{c}\text { The set surface of the } \\
\text { soil ,mm }\end{array}$ & 15 & 3 & 5 & 8 & 13 & 20 & 20 & 20 & 20 \\
\hline
\end{tabular}

Based on these studies, it can be concluded that, in contrast to non-cohesive soils that can condense immediately after a structural disturbance, water saturation cohesive soils simultaneously with the compaction process undergo complex internal transformations caused by a violation of their cohesion in the conditions of concussion. shown

Let us turn to Figure 1, where the graph of the dependence of $l=f(t)$ for $\alpha=$ const is 


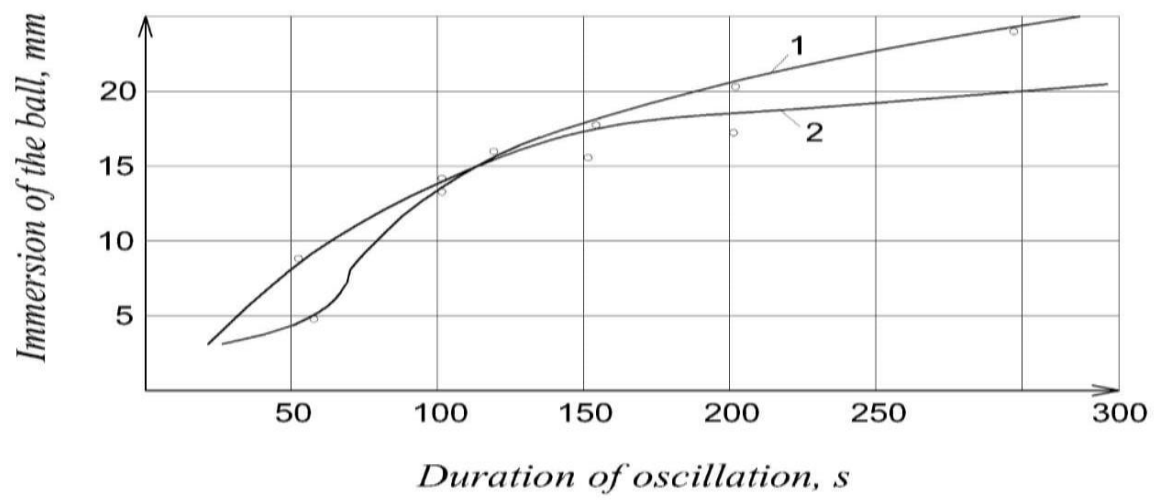

Fig. 1. The nature of the ball's immersion in the ground during prolonged shaking a $=2200 \mathrm{~mm} / \mathrm{s}^{2}$. The numbers indicate the numbers of the tested soils.

As follows from the graph, along with the value of the calculated acceleration, the duration of its impact is also very important, depending on which the degree of violation of the structure (cohesive) of the soil increases.

Analysis of the results of the experiments showed that the decrease in the cohesion of the soil and its transition to a liquefied state generally depends on the state of humidity, water-colloidal minerals, grading composition, the content of various salts, as well as on the intensity and nature (in frequency and amplitude) of the shock applied to the soil. At the same time, direct dependence of the ball's immersion in the soil on the intensity of the concussion is established.

It was also important to determine the transition rate of the soil to a liquefied state, depending on the intensity of the shaking. Several experiments were conducted with various types of soils (sandy loam, loam, clay) in this direction. The essence of these experiments consisted, as in other experiments, in observing (in time) the immersion of a ball sunk into a sample of the test soil. The sample in this form was subjected to a very different dynamic effect in intensity, one of the results of which is illustrated in Fig.2.

As can be seen from the graph, with an increase in the calculated acceleration $\left(a_{c}\right)$ value, the degree of destruction of the soil cohesion increases.
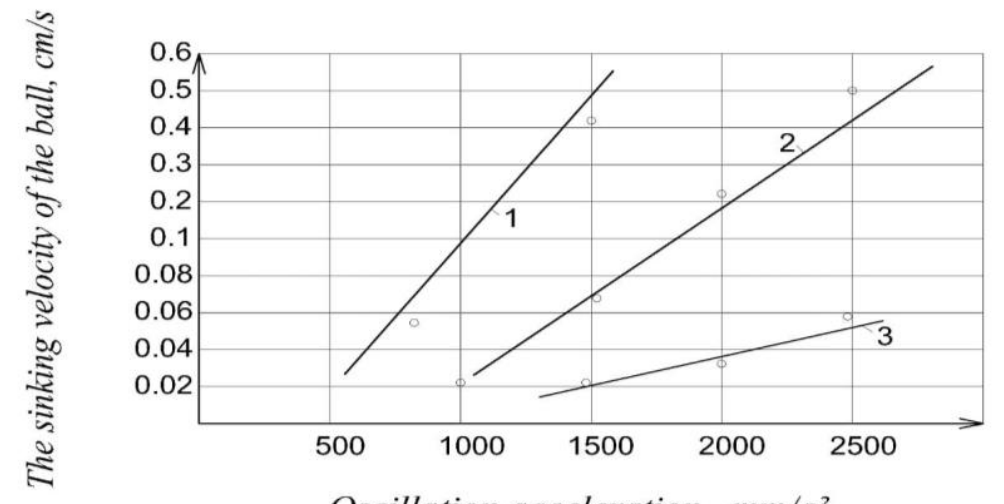

Oscillation acceleration, $\mathrm{mm} / \mathrm{s}^{2}$

Fig. 2. Graph of the dependence of the speed of the ball's immersion in the soil on the intensity of the concussion at $\mathrm{P}=1,0.10^{5} \mathrm{~N} / \mathrm{m}^{2}$. The numbers $1,2,3$ correspond to the numbers of the soils. 
At the same time, the effect of weakening the strength (shear resistance) of the soil by reducing its connectivity also depends on the simultaneous reduction of the influence of normal stress due to the weighing effect of the backpressure $\left(\Delta h_{z}\right)$ caused by the dynamic pressure. The value of the dynamic pressure, along with the filtration property of the soil, also depends on the compaction rate of the soil (dynamic compaction coefficient $v_{n}$ ), which increases with increasing uniformity and porosity of the soil, as well as the intensity and duration of the vibration.

Figure 3 illustrates the graph of the dependence of $v_{n}$ on the porosity of various soils. At the same time, the extremely high value of $v_{n}$ corresponds to the maximum

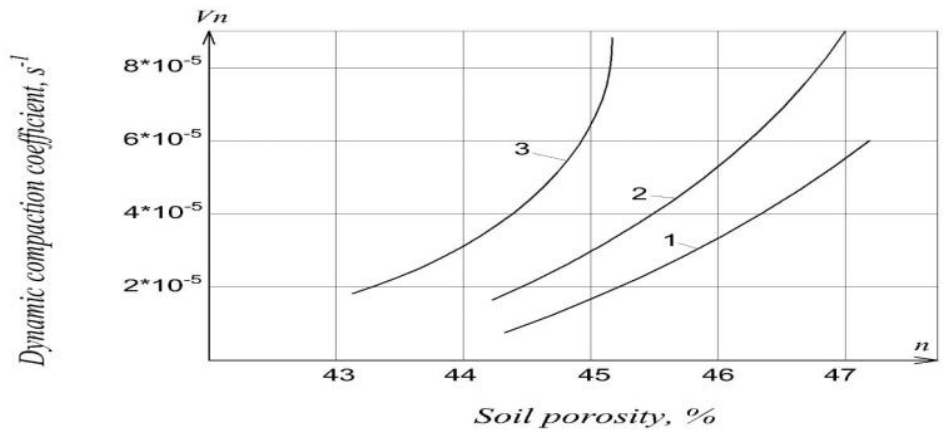

Fig.3. The nature of the change in the dynamic compaction coefficient $v_{n}$ from porosity for loess soils.

The porosity of the soil and a slight increase in density (decrease in porosity) in these conditions leads to a sharp decrease in the dynamic compaction coefficient.

The influence of the concussion intensity on the dynamic compaction coefficient $v_{n}$ is seen in table 2.

As a result of experiments conducted with water-saturated $(\mathrm{G}=0.92-0.96)$ loess soils, it was found that the dynamic pressure $h_{z}$, which occurs during the compaction of the soil, has a gradually increasing character. The beginning of the dynamic pressure in the experimental conditions corresponds to 10-20 s after the application of the dynamic load on the soil.

Table 2. Dependence of the dynamic compaction coefficient on the intensity of loess soil shaking

\begin{tabular}{|c|c|c|c|c|}
\hline \multirow{2}{*}{$\begin{array}{c}\text { Acceleration, } \\
\mathrm{mm} / \mathrm{s}^{2}\end{array}$} & 44 & 45 & 46 & 47 \\
\cline { 2 - 5 } & - & 0.000005 & 0.000012 & 0.000020 \\
1500 & - & 0.00011 & 0.000019 & 0.000032 \\
2500 & 0.00001 & 0.00003 & 0.000057 & 0.000090 \\
\hline
\end{tabular}

The analysis of these experiments allowed us to draw up the following scheme of processes that continuously occur to varying degrees during the shaking of water-saturated $(\mathrm{G}>0.8)$ loosely cohesive soils:

a) gradual weakening of internal cohesions;

b) the formation of a filtration flow with ascending currents (dynamic head) as a result of compaction of broken particle bonds;

c) the increasing nature of the fall in the overall strength of the soil due to the simultaneous weakening of the cohesion and the weighing effect of the dynamic pressure $h_{z}$.

According to this scheme, the value of the dynamic head should be very important as a factor involved in reducing the overall strength of the soil during the shaking process.

The graph (Figure 4) shows the data of recording changes in dynamic pressures over 
time for some varieties of the studied loess. The soil had been shaking with an intensity determined by the acceleration of $2200-2500 \mathrm{~mm} / \mathrm{s}^{2}$.

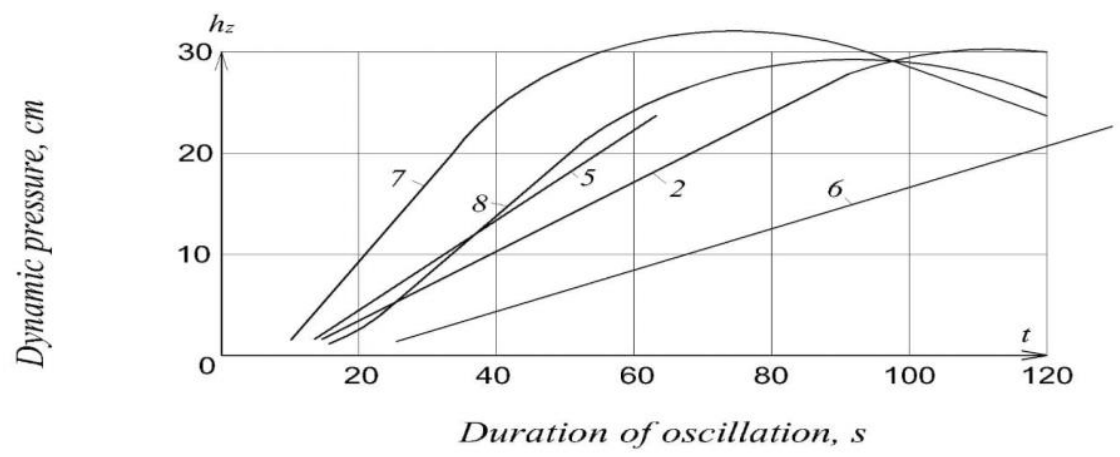

Fig. 4. Dependence of the form $h_{z}=f(t)$ for the studied soils $(z=30 \mathrm{~cm})$. The curves indicate the soils of the soil numbers.

As can be seen from the dependence $h_{z}=f(t)$ to dynamic pressure at the horizon has reached a maximal value at a specific intensity of shaking, requires some period, measured in tens of minutes.

The quantity of this segment under the same conditions of shaking is different for different soils, probably due to these cohesions' strength.

\section{Conclusion}

1. The liquefaction of cohesive soils under dynamic impacts is significantly different from the liquefaction of sand, characterized by mechanical destruction of the structure.

2. The process of liquefaction of cohesive soils is accompanied by complex physical and chemical phenomena caused by a gradual change in the connectivity of the soil, compaction of destroyed particles, the presence of a filtration flow, and the effect of backpressure, etc.

3. The decrease in soil connectivity and its transition to a liquefied state generally depends on the state of humidity, water-colloidal minerals, gradual composition, the content of various salts, and the intensity and nature (in frequency and amplitude) of the dynamic load applied to the soil.

4. The rate of transition of the soil to the liquefied state is determined by the coefficient of dynamic compaction and the shaking intensity.

5. The determination of soil cohesion and dynamic pressure values is important in assessing the state of soil liquefaction in the body of dams constructed from clay soils in seismic areas.

\section{References}

1. Voznesenskiy Y.A. Zemletryaseniya i dinamika gruntov, Sorosovskiy obrazovatel'nyy zhurnal, № 2, pp.101-108, (1998)

2. Agayeva L.A. Inzhenerno-geologicheskiye usloviya i otsenka seysmicheskoy opasnosti ploshchadki mosta cherez proliv Karabogazgol, Innovatsionnyye 
tekhnologii v reshenii aktual'nykh problem seysmologii, gidrogeologii i inzhenernoy geologii, Materialy mezhdunarodnoy nauchnoy konferentsii, posvyashchennoy 110letiyu akademika G.A. Mavlyanova, pp.8-11, (2020)

3. Dzhurik V.I., Drennov A.F., Serebrennikov S.P., Bryzhak Y.V., Yeskin A.Y. Izucheniye dinamicheskikh kharakteristik zemletryaseniy, Baykal'skoy riftovoy zony $\mathrm{s}$ tsel'yu formirovaniya iskhodnykh seysmicheskikh signalov, Vulkanologiya i seysmologiya, № 5, pp.1-11, (2015)

4. Kopylova G., Boldina S. Anomalies in Groundwater Composition Caused by Earthquakes: Examples and Modeling Issues, E3S Web of Conferences 98, 01029 (2019), https://doi.org/10.1051/e3sconf/20199801029 WRI-16.

5. Ishikhara K. Povedeniye gruntov pri zemletryaseniyakh (Prevod s angliyskogo po litsenzii izdatel'stva «Oxford University Press» pod red. prof.Fadeyeva), SanktPeterburg, p.383, (2006)

6. Kokusho T. Strain- depended soil properties optimized from distractive Earthquake records compared with laboratory date. "Geotechnical aspects of natural and Manmade disasters", Proc. of International Geotechnical Symposium, pp.17-25, Astana, (2005)

7. Kazama M., Sento N., Omura H., Toyota H., M. Kitazume Liquefaction and settlement of reclaimed ground with gravelly decomposed granite soil Soils Found., 43 (3), pp.57-72, (2003)

8. Kazama M., Yamakawa Y., Yamaguchi A., Yamada S., Kamura A., Hino T., Moriguchi S. Disaster report on geotechnical damage of Miyagi prefecture in Japan, caused by Typhoon Hagibis in (2019)

9. Lingwei K., Zsilang S., Aiguo G. Influence of stress ratio and moisture condition of loose deposit on dynamic parameters and ground response spectrum, Proc. of the 15th Asian Regional Conference on Soil Mechanics and Geotechnical Engineering. Japanese Geotechnical Society, SIMSG, ISSMGE Fukuoka Japan: 9

10. Seed H.B., Harder L.F. SPT-based analysis of cyclic pore pressure generation and undrained residual strength, Proceedings of the B. Seed memorial Symposium, 2, pp.351-376, (1990)

11. Wurman G. Earthquake Early Warning and the Physics of Earthquake Rupture, A dissertation submitted in partial satisfaction of the requirements for the degree of Doctor of Philosophy. University of California, p. 97, Berkeley, (2010)

12. Eduardo M. Sosa, Luis A. Godoy. Nonlinear dynamics of above-ground thin-walled tanks under fluctuating pressures, Journal of Sound and Vibration, 283(1-2), pp.201215, (2005)

13. Gupta H.K., A review of recent studies of triggered earthquakes by artificial water reservoirs with special emphasis on earthquakes in Koyna, India. EarthScience Reviews 58 (3-4), pp.279-310, (2002)

14. Kato T., Honda T., Kawato S. The seismic analysis of an earth-fill dam on thick liquefiable ground and countermeasures against a large earthquake, International Symposium on «Appropriate technology to ensure proper Development, Operation and Maintenance of Dams in Developing Countries» Johannesburg, South Africa, 18 (2016)

15. Atabekov I.U., Earth Crust's stresses variation in Central Asian earthquake's region, J. Geodesy and Geodynamics. 11,(4), pp. 293-299, (2020) https://doi.org/10.1016/j.geog.2019.12.005.

16. Rasulov H., Articbayev D. Criteria of slopes stability at seismic fluctuation, OEAPS Inc. (Open European Academy of public sciences). Fundamental and applied scientific research, International scientific and practical conference Berlin, Germany, pp.68-71, (2019) 
17. Rasulov H., Rasulov R. Increment of seismicity of the building area depending on soil conditions, Extended Abstracts ofthe 15th Asian Regional Conference on soil mechanics and Geotechnical Engineering, Japanese Geotechnical Society, p. 88, (2015)

18. Rasulov R.Kh. Seismic subsidence deformation of moisturized loess, J. "European Science Review", pp.290-292

19. Rasulov KH.Z. Seysmoprochnost' i seysmoprosadka lessovykh gruntov.- Tashkent: Izd-vo «Fan» Akademii nauk Respubliki Uzbekistan, p. 335, (2020)

20. Articbayev D., Rasulov H., Baibolov K. Influence of Soil Density and Moisture on Seismic Stability of Slope Structures. International Journal of Engineering Research and Technology, 12, pp.1259-1262, (2019) 